\title{
Stabilization of spine Synaptopodin by mGluR1 is required for mGluR-LTD
}

Running Title: Spine Synaptopodin rules of mGluR-LTD

Luisa Speranza ${ }^{1}$, Yanis Inglebert ${ }^{2}$, Claudia De Sanctis ${ }^{1}$, Pei You Wu ${ }^{2}$, Magdalena Kalinowska ${ }^{1}$,

\author{
R. Anne McKinney ${ }^{2 *}$, Anna Francesconi ${ }^{1 *}$
}

${ }^{1}$ Dominick P. Purpura Department of Neuroscience, Albert Einstein College of Medicine, New

11 York, NY 10461 US; '2Department of Pharmacology \& Therapeutics, McGill University, Montreal, 12 QC H3G OB1 CA

\section{${ }^{*}$ Corresponding Authors}

16 Anna Francesconi, Ph.D.

17 R. F. Kennedy Bldg. Room 706

181410 Pelham Parkway South

19 Albert Einstein College of Medicine

20 New York, NY 10461, USA

21 anna.francesconi@einsteinmed.org

22 Tel: +17184302258

\author{
R. Anne McKinney, D.Phil \\ Bellini Life Science Bldg. Room 167 \\ 3649 Promenade Sir William Osler \\ McGill University \\ Montreal, Quebec, H3G0B1, CA \\ anne.mckinney@mcgill.ca \\ Tel: +15143985685
}

Keywords: Dendritic spines, Synaptopodin, spine apparatus, metabotropic glutamate receptors, mGluR1, mGluR-LTD, lysosome, protein turnover

Conflict of interest: The authors declare no competing financial interests

33 Acknowledgments: We thank members of the Francesconi and McKinney labs for comments on 34 the manuscript. We would like to thank Francois Charron for his excellent technical assistance. 35 Supported by NIMH R01MH108614 (A.F.), CIHR MOP 86724 (R.A.M.) and The Norman 36 Zavalkoff Family Foundation (R.A.M). We acknowledge the assistance of the Neural Cell 37 Engineering and Imaging Core of the Einstein Rose F. Kennedy Intellectual and Developmental Disabilities Research Center supported by NICHD U54 HD090260. 


\section{Abstract:}

40 Dendritic spines, actin-rich protrusions forming the postsynaptic sites of excitatory synapses, 41 undergo activity-dependent molecular and structural remodeling. Activation of group 1

42 metabotropic glutamate receptors - mGluR1 and mGluR5 - by synaptic or pharmacological

43 stimulation, induces LTD but whether this is accompanied with spine elimination remains

44 unresolved. A subset of telencephalic mushroom spines contains the spine apparatus (SA), an

45 enigmatic organelle composed of stacks of smooth endoplasmic reticulum, whose formation 46 depends on the expression of the actin-bundling protein Synaptopodin. Allocation of

47 Synaptopodin to spines appears governed by cell-intrinsic mechanisms as the relative 48 frequency of spines harboring Synaptopodin is conserved in vivo and in vitro. Here we show 49 that expression of Synaptopodin/SA in spines is required for induction of mGluR-LTD at 50 Schaffer collateral-CA1 synapses. Post-mGluR-LTD, mushroom spines lacking 51 Synaptopodin/SA are selectively lost whereas spines harboring it are preserved, a process 52 dependent on activation of mGluR1 but not mGluR5. Mechanistically, we find that mGluR1

53 supports physical retention of Synaptopodin within excitatory spine synapses during LTD while 54 triggering lysosome-dependent degradation of the protein residing in dendritic shafts. Together, 55 these results reveal a cellular mechanism, dependent on mGluR1, which enables selective 56 preservation of stronger spines containing Synaptopodin/SA while eliminating weaker ones and 57 potentially countering spurious strengthening by de novo recruitment of Synaptopodin. Overall 58 our results identify spines with Synaptopodin/SA as the locus of mGluR-LTD and underscore 59 the importance of the molecular microanatomy of spines in synaptic plasticity. 


\section{Introduction}

74 Dendritic spines, small protrusions on excitatory neurons, serve as the sites for structural 75 changes during long-term changes in synaptic strength. The mechanisms of long-term 76 potentiation (LTP) associated with spine outgrowth and enlargement (Harris, 2020) are well 77 understood, whereas the occurrence of structural changes in spines after long-term depression 78 (LTD) is more controversial and the underlying mechanisms not fully understood (Stein \& Zito, 79 2019). In some incidences spines are eliminated or reduced in size after LTD but in other cases 80 synaptic weakening can occur independently of spine shrinkage (Thomazeau et al, 2020; Wang 81 et al, 2007). This complexity is compounded by the heterogeneous microanatomy of spines 82 (Berry \& Nedivi, 2017), with some marked by transient or enduring presence of smooth 83 endoplasmic reticulum (sER) (Perez-Alvarez et al, 2020; Spacek \& Harris, 1997). In 84 telencephalic regions, a subset of large spines contain a spine apparatus (SA) (Spacek, 1985; 85 Spacek \& Harris, 1997), a poorly understood neuron-specific sER organelle that supports local $86 \mathrm{Ca}^{2+}$ storage (Fifková et al, 1983; Korkotian et al, 2014). The SA, which is present in $\sim 10-20 \%$ of 87 adult hippocampal and cortical mature spines (Spacek \& Harris, 1997), is made of stacks of 88 sER tubules intercalated with F-actin and Synaptopodin (Synpo), an F-actin-bundling protein 89 (Asanuma et al, 2005; Deller et al, 2000). Synpo is necessary and sufficient for the formation 90 and maintenance of the SA, as shown by absence of the organelle in mice lacking Synpo 91 (Deller et al, 2003). At present, the contribution of the SA to forms of activity-dependent synaptic 92 plasticity is incompletely understood and the mechanisms underlying enduring presence of 93 Synpo in subsets of dendritic spines remain unclear.

Activation of group 1 metabotropic glutamate receptors (Gp1 mGluRs) - mGluR1 and mGluR5 by synaptic or pharmacological stimulation, induces LTD at Schaffer collateral-CA1 synapses (mGluR-LTD) (Lüscher \& Huber, 2010), a form of plasticity altered in many neurodevelopmental disorders (Huber et al, 2002; Sahin \& Sur, 2015). It was further shown that the capacity of Gp1 mGluRs to depress synaptic transmission relies on sER (Holbro et al, 2009), but whether presence of Synpo is needed for mGluR-LTD to occur is untested. Gp1 mGluRs are critical to 102 dependent shrinkage of large spines (Oh et al, 2013) and heterosynaptic structural plasticity (Oh 103 et al, 2015). Nevertheless, the impact of mGluR-LTD on spine elimination was recently 104 questioned, since contrasting observations have reported either spine loss induced by mGluR105 LTD (Ramiro-Cortés \& Israely, 2013; Wiegert \& Oertner, 2013) or lack of effect on spine density 
106 (Thomazeau et al, 2020). Moreover, whether spines containing the SA undergo structural

107 remodeling during mGluR-LTD is unknown.

Here we show that expression of Synpo/SA in spines is required for induction of mGluR-LTD at

110 hippocampal Schaffer collateral-CA1 synapses. We find that mGluR-LTD induces selective loss

111 of mushroom spines that do not contain Synpo, an effect mediated by mGluR1. We further

112 report that mGluR-LTD triggers selective degradation of Synpo in dendritic shafts via the

113 lysosomal pathway, whereas Synpo at spine synapses is stabilized through association with

114 mGluR1. Together, these findings uncover a novel cellular mechanism dependent on mGluR1

115 that enables selective preservation of spines containing the SA while eliminating weaker ones.

Materials and Methods

ANIMALS

122 All procedures were according to protocols approved by the Albert Einstein College of Medicine,

123 in accordance with the Guide for the Care and Use of Laboratory Animals by the United States

124 PHS or the guidelines of the Canadian Council on Animal Care and the McGill University 125 Comparative Medicine and Animal Resources animal handling protocols 5057. Sprague Dawley 126 rats were used for primary neuronal cultures. Grm1 knockout mice (Grm ${ }^{\mathrm{KO}}$ (Mende et al, 127 2016)) and Synpo knockout mice (Deller et al, 2003) crossed with L15 GFP-expressing mice 128 used as wild type (Verbich et al, 2016) as previously described. Mice of both sexes were used 129 for experiments, fed ad libitum and housed with a $12 \mathrm{~h}$ light/dark cycle.

\section{ELECTROPHYSIOLOGY}

133 Hippocampal slices were obtained from P 30 to 40 old Synpo KO or L15 mice. Mice were 134 deeply anaesthetized with isoflurane and killed by decapitation. Slices $(400 \mu \mathrm{m})$ were cut on a 135 vibratome (Leica VT1200S) in an sucrose-based solution containing (in mM) 280 sucrose, 26 $136 \mathrm{NaHCO}_{3}, 10$ Glucose, $1.3 \mathrm{KCl}, 1 \mathrm{CaCl}_{2}$ and $10 \mathrm{MgCl}_{2}$ and were transferred at $32^{\circ} \mathrm{C}$ in regular 137 artificial cerebrospinal fluid (ACSF) containing (in mM) $124 \mathrm{NaCl}, 5 \mathrm{KCl}, 1.25 \mathrm{NaH} 2 \mathrm{PO}$, 2 $138 \mathrm{MgSO} 4,26 \mathrm{NaHCO}$, $2 \mathrm{CaCl}$, and 10 glucose saturated with 95\% O2/5\% CO2 (pH 7.3, 300 $139 \mathrm{mOsm})$ for 15 minutes before resting at room temperature for $1 \mathrm{~h}$ in oxygenated $(95 \%$ O2/5\% 
140 CO2) ACSF. For recording, slices were transferred to a temperature-controlled $\left(32^{\circ} \mathrm{C}\right)$ chamber 141 with oxygenated ACSF. To assess mGluR-LTD, slices were placed into a heated $\left(31-32^{\circ} \mathrm{C}\right)$ 142 recording chamber of an upright microscope (DM LFSA Microsystems, Heidelberg, Germany) 143 and perfused continuously with regular ACSF. Field excitatory postsynaptic potentials (fEPSPs) 144 were recorded in the stratum radiatum of the CA1 region by using glass microelectrodes filled 145 with $3 \mathrm{M} \mathrm{NaCl}$. $\mathrm{GABA}_{\mathrm{A}}$ receptor-mediated inhibition was blocked with $100 \mu \mathrm{M}$ picrotoxin and the 146 area CA1 was surgically isolated from CA3 to avoid epileptiform activity. fEPSPs were elicited at $1470.1 \mathrm{~Hz}$ by a digital stimulator that fed by a stimulation isolator unit. All data analyses were 148 performed with custom written software in Igor Pro 8 (Wavemetrics). fEPSP slope was 149 measured as an index of synaptic strength.

\section{NEURONAL CULTURES AND DRUG TREATMENTS}

Hippocampi and cortices from newborn rat pups dissected in $\mathrm{Ca}^{2+/} \mathrm{Mg}^{2+}$-free $\mathrm{HBSS}$ were 154 digested with $0.25 \%$ trypsin and DNAse $(2000 \mathrm{U} / \mathrm{ml})$ for $20 \mathrm{~min}$ at $37^{\circ} \mathrm{C}$ and mechanically 155 triturated. Viable cells, determined by trypan blue dye exclusion, were plated at $8 \times 10^{4} / 1.13 \mathrm{~cm}^{2}$ 156 on poly-L-lysine-coated cover glasses and at $2.5 \times 10^{5} / 1.9 \mathrm{~cm}^{2}$ in multi-well plates. Cells were 157 maintained at $37^{\circ} \mathrm{C}, 5 \% \mathrm{CO}_{2}$ in serum-free Neurobasal A medium with $2 \%$ B-27 supplement, 2 $158 \mathrm{mM}$ GlutaMax (from Invitrogen), penicillin $(50 \mathrm{U} / \mathrm{ml})$, streptomycin $(50 \mu \mathrm{m} / \mathrm{ml})$. After 5 days in 159 vitro, a mix of $37 \mathrm{mM}$ Uridine and $27 \mathrm{mM}$ 5-Fluoro-2-deoxyuridine was added; half medium was 160 replaced weekly and neurons used at 19-21 days in vitro.

161 For chemical mGluR-LTD, cells were rinsed with pre-warmed medium and treated with $50 \mu \mathrm{M}$

162 S-DHPG (Tocris Bioscience) or vehicle for $15 \mathrm{~min}$ at $37^{\circ} \mathrm{C}$ : cells were rinsed with pre-warmed 163 medium and incubated with fresh medium for 30 or $120 \mathrm{~min}$ at $37^{\circ} \mathrm{C}$. Bay $36-7620$ or MPEP

164 (Tocris Bioscience) were applied alone for $15 \mathrm{~min}$ at $37^{\circ} \mathrm{C}$ or together with DHPG and added to 165 the fresh medium during recovery. For treatment with MG132 (ApexBio), leupeptin or Baf $A_{1}$ 166 (Sigma Aldrich), after rinsing with pre-warmed medium, drugs or respective vehicle were applied 167 alone in fresh medium for $15 \mathrm{~min}$ at $37^{\circ} \mathrm{C}$ or together with DHPG, and added to fresh medium 168 during recovery. For treatment with rapamycin (Cayman Chemical) or cycloheximide (Sigma 169 Aldrich), cells were rinsed with pre-warmed medium and drugs or vehicle applied in fresh 170 medium for the indicated times at $37^{\circ} \mathrm{C}$. After treatments, cells were placed on ice and 171 processed for downstream analysis.

172

173 DilC $_{18}$ LABELING 
175 Cells and tissue sections were labeled with the fluorescent dye 1,1'-Dioctadecyl-3,3,3',3'176 Tetramethylindotricarbocyanine lodide $\left(\mathrm{DilC}_{18}\right.$; Molecular Probes, crystals cat. D3911) as 177 described (Cheng et al, 2014). Briefly, cells plated on cover glasses were fixed with $4 \%$ 178 paraformaldehyde (PFA) for $10 \mathrm{~min}$ and washed with PBS. After PBS aspiration, DilC 18 crystals 179 (3-4 crystals/well) were sprinkled over the cells with a 18 gauge needle. To prevent dehydration, 180 PBS was added to the wells and the plate incubated for $10 \mathrm{~min}$ on an orbital shaker at RT 181 protected from light. After washing with PBS to remove the crystals, cells were incubated in PBS 182 overnight at RT and washed three times with PBS (5 min per wash) before immunolabeling or 183 mounting on glass slides. For tissue sections, mice were anesthetized with isoflurane and 184 perfused with 4\% PFA: the brain was removed and post-fixed with $4 \%$ PFA overnight at $4{ }^{\circ} \mathrm{C}$. 185 After three 5 min washes with PBS, 150 or $300 \mu$ m-thick coronal sections were cut with a 186 vibratome (Leica VT1000S). The tissue was gently unfolded with a paintbrush and crystals of 187 DilC $_{18}$ applied with a needle onto the regions of interest (parietal and prefrontal cortex). Labeled 188 tissue sections were incubated at $4^{\circ} \mathrm{C}$ in PBS, protected from light, for 7 to 10 days before 189 image acquisition.

\section{IMMUNOFLUORESCENCE}

Cells were rinsed in PBS for 2 min and fixed in 4\% PFA for 10 min at RT. After permeabilization with $0.1 \%$ Triton X-100 in PBS for 15 min, cells were incubated for $1 \mathrm{~h}$ at RT with blocking solution of either $5 \%$ bovine serum albumin (BSA) or $5 \%$ normal serum. Primary antibodies in blocking solution were applied overnight at $4^{\circ} \mathrm{C}$. After three washes with PBS for 3 minutes, cells were incubated for 1-2 $\mathrm{h}$ at RT with fluorophore-conjugated secondary antibodies, washed three times with PBS and mounted on glass slides with Prolong (Invitrogen). To label surface AMPARs, cells were rinsed two times with pre-warmed medium and incubated for $30 \mathrm{~min}$ at $37^{\circ} \mathrm{C}$ with rabbit anti-GluA1 (1/150; Calbiochem/Millipore, RRID: AB_564636) in culture medium. After incubation with anti-GluA1, cells were treated with $50 \mu \mathrm{M}$ DHPG or vehicle for 15 min at $37^{\circ} \mathrm{C}$, rinsed with pre-warmed medium, and incubated with fresh medium for $30 \mathrm{~min}$ at $37^{\circ} \mathrm{C}$. Cells were then washed with PBS containing $1 \mathrm{mM} \mathrm{MgCl}, 0.1 \mathrm{mM} \mathrm{CaCl}_{2}$ and fixed with 4\% PFA for $10 \mathrm{~min}$. After fixation, cells were washed with PBS (3x $5 \mathrm{~min}$ ), incubated with 5\% BSA for $1 \mathrm{~h}$ at RT and with secondary fluorescent antibody for $1 \mathrm{~h}$ at RT. After washing with PBS, cells were permeabilized, blocked and incubated with primary antibodies as above. The 
208 AB_887825), guinea pig anti-Synaptopodin (1/500; Synaptic Systems, RRID: AB_10549419) 209 chicken anti-MAP2 (1/500; PhosphoSolutions, RRID: AB_2138173), rabbit anti-mGluR1 210 (1/2,000; RRID: AB_2571735). The following secondary antibodies were used: donkey anti211 mouse or rabbit conjugated to Alexa Fluor 488 and Alexa Fluor 647, goat anti-guinea pig Alexa 212 Fluor 488 (Invitrogen), donkey anti-chicken $\lg$ conjugated to Alexa Fluor 647 and

213 Aminomethylcoumarin Acetate (Jackson ImmunoResearch Labs)

MICROSCOPY

Wide field fluorescence imaging was carried out with an Olympus IX81 inverted microscope equipped with digital CCD ORCA-R2 camera (Hamamatsu) using 40x (N.A.=1.3) or 60x (N.A.=1.35) oil objectives. Confocal images were acquired with a Zeiss LSM880 Airyscan using a Plan-Apochromat 63x (N.A.=1.4) oil immersion objective; a $561 \mathrm{~nm}$ diode pumped solid-state laser (DPSS 561-10) was used to visualize DilC 18 . Images at $1024 \times 1024$ pixel resolution were acquired with scan speed set at 6 and pinhole configured to 1 Airy unit for each channel. Stacks

223 of images were acquired with a $0.5 \mu \mathrm{m} \mathrm{Z}$ step and reconstructed with the Fiji's Stacks $Z$ Project

224 function to generate Z-stack projections of the maximum intensity.

IMAGE ANALYSIS

Analysis was carried out blind to treatment/genotype using the image-processing platform Fiji (Schindelin et al, 2012). To quantify Synpo clusters, a mask of the outline of neurons was generated using MAP2 signal overlay. After background subtraction, individual clusters within the masked region were measured by automated count using the Analyze Particles function on thresholded images. For spine analysis, dendrites and dendritic protrusions were outlined and measured with the segmented line tool. Proximal dendritic segments $(\sim 100 \mu \mathrm{m})$ were analyzed

234 in both primary and secondary dendrites. Spine density is expressed as number of spines per

$23510 \mu \mathrm{m}$ of dendritic length. To classify dendritic spines, the length $(I)$ head width $(h)$ and neck 236 width $(n)$ were manually traced for individual dendritic protrusions. Spine length was measured 237 from the emerging point on the shaft to the tip of spine head, and head diameter was measured 238 at the point of maximum width. Dendritic protrusions were classified according to established 239 morphological criteria (Harris et al, 1992; Zagrebelsky et al, 2005) and defined as mushroom 240 spines when $h » n(h / n>1.5)$ and thin spines when $I>1 \mu \mathrm{m}$ and $h / n \leq 1.5$. Stubby spines and 
241 filopodia were rarely observed in the mature neurons used in the study and not included in the

242 analysis.

WESTERN BLOT AND IMMUNOPRECIPITATION

Drug-treated cortical neurons were placed on ice, rinsed with ice-cold PBS and lysed in buffer of $20 \mathrm{mM}$ MOPS ( $\mathrm{pH}$ 7.2), 2 mM EGTA, 5 mM EDTA, 1\% Triton X-100 supplemented with a cocktail of protease and phosphatase inhibitors. Cells were incubated on ice for 5 min, scraped off the wells, and collected by centrifugation at $21,000 \times g$ at $4^{\circ} \mathrm{C}$ for $15 \mathrm{~min}$. Equal amount of proteins were resolved by SDS-PAGE and processed by Western blot assay per standard protocols using horseradish peroxidase-conjugated secondary antibodies and ECL for detection on film or with an Azure c600 imaging system (Azure Biosystems). The following primary antibodies were used: rabbit anti-Synaptopodin (1/1000), goat anti-Synaptopodin (1/200; Santa Cruz Biotech, RRID: AB_2201166), rabbit mGluR1 (1/500, Alomone labs, RRID:AB_2039984; 1/10,000 RRID:AB_2571736), mouse anti-PSD95 (1/400; Antibodies Inc., RRID: AB_2292909), mouse anti- $\gamma$-Tubulin (1/2,500; Sigma Aldrich, RRID: AB_477584).

257 For immunoprecipitation, brain cortices of adult mice were homogenized on ice in a buffer of 20 $258 \mathrm{mM}$ Tris- $\mathrm{HCl}, 5 \mathrm{mM}$ EDTA, $100 \mathrm{mM} \mathrm{NaCl}, 1 \%$ Triton $\mathrm{X}-100,0.5 \%$ sodium deoxycholate $(\mathrm{pH} 7.4$; $10 \mu \mathrm{l} / \mathrm{mg}$ tissue), supplemented with cocktails of protease and phosphatase inhibitors. The tissue was manually homogenized on ice, centrifuged at $13,000 \times \mathrm{g}$ for $20 \mathrm{~min}$ at $4^{\circ} \mathrm{C}$ and supernatant collected. Equal amounts of protein were incubated overnight at $4^{\circ} \mathrm{C}$ with primary antibodies (rabbit anti-Synaptopodin $3 \mu \mathrm{l} / \mathrm{mg}$; goat anti-Synaptopodin $2 \mu \mathrm{g}$ ) or control $\lg$ coupled to Protein G-coupled magnetic beads (Dynabeads, Life Technologies). Unbound material was removed and the beads washed three times with homogenization buffer, three times with PBS/0.1\% Triton X-100 and one time with PBS before elution in denaturing sample buffer at $95^{\circ} \mathrm{C}$ for $5 \mathrm{~min}$.

Unless noted, values were imported into Prism 8.1 (GraphPad) for the generation of graphs and statistical tests. Data are reported as mean \pm SEM unless indicated: normality and data distribution were assessed with the Kolmogorov-Smirnov test. Two-tailed Student $t$-test was used to compare two groups and Mann-Whitney test used for non-parametric analysis of ranks

274 when appropriate. One-way ANOVA with Tukey's post-hoc test was used to compare multiple 
275 groups. Gardner-Altman estimation plots used to display spine data and the two-sided

276 permutation $t$-test, were generated with the web application estimationstats.com (Ho et al, 277 2019). $P$ value $<0.05$ was considered significant in all statistical comparisons.

\section{Results}

Dendritic spines are the sites of excitatory synapses and their structural and functional properties are modified in response to activity patterns that produce long-term changes in synaptic transmission. Low frequency stimulation was shown to selectively induce depression of evoked EPSCs in dendritic spines containing sER, an effect that was blocked by Gp1 mGluR antagonists (Holbro et al, 2009). Although this finding suggested that Gp1 mGluR-induced synaptic depression could be compartmentalized to spines endowed with ER, whether the presence of Synpo is required for mGluR-LTD and if it plays a role in spine elimination after mGluR-LTD is currently unknown. To address this question, we used DHPG (RS-DHPG; 100 $\mu \mathrm{M}, 5 \mathrm{~min}$ ) to induce mGluR-LTD at stimulated Schaffer collateral (SC)-CA1 synapses (Fig. 1A)

292 in hippocampal slices from WT and Synpo knockout mice $\left(\right.$ Synpo ${ }^{\mathrm{KO}}$ ) which lack the SA (Deller 293 et al, 2003). In WT, DHPG induced rapid and enduring depression of evoked field potential 294 (fEPSP) slope values compared to baseline, as measured 35 min post-DHPG (fEPSPs to 69\% $295 \pm 6$ of baseline, $n=9$; Fig. $1 B, C)$. In contrast, in Synpo ${ }^{\mathrm{KO}}$ mice the capacity of DHPG to produce 296 LTD was drastically impaired (depression of fEPSPs to $87 \pm 3 \%$ of baseline, $n=9$; Fig. 1B,C).

297 Thus this finding indicates that expression of Synpo and presence of the SA is required for 298 efficient mGluR-LTD at SC-CA1 synapses.

NMDAR-dependent long-term depression was shown to causes spine shrinkage and elimination (Stein \& Zito, 2019), but whether mGluR-LTD is accompanied with spine elimination remains controversial. Both spine shrinkage and elimination (Ramiro-Cortés \& Israely, 2013) and, conversely, absence of changes in structural plasticity and spine density (Thomazeau et al, 2020) were reported in response to Gp1 mGluR activation. In addition, the specific impact of mGluR-LTD on spines containing Synpo/SA is unknown. Synpo is expressed in spines, starting around postnatal day 12, and is most abundant in the adult brain (Czarnecki et al, 2005). Remarkably, its developmental regulation is mirrored in primary neurons (Konietzny et al, 2019), 
309 at $\sim 3$ weeks. Congruent with its intrinsic association with the SA, Synpo occupies the neck and 310 head of mushroom spines (Fig. 1D), $\sim 50 \%$ of which are of size comparable to mushroom 311 spines lacking Synpo so that they are not distinguishable based on morphology alone (Fig. 1D).

312 To examine the impact of mGluR-LTD on spine structural plasticity and elimination, we used 313 sparse labeling with the fluorescent lipophilic dye DilC $_{18}$ and high-resolution microscopy to 314 survey density and structural properties of spines under physiological conditions that preserve 315 actin dynamics (McKinney, 2010; Roelandse \& Matus, 2004) and rate of protein synthesis 316 (Cooke et al, 2019), both crucial for structural and functional plasticity (Cingolani \& Goda, 2008; 317 Huber et al, 2000). Widespread chemical mGluR-LTD was produced by transient stimulation 318 with S-DHPG (50 $\mu \mathrm{M}, 15 \mathrm{~min})$ followed by recovery for 30 or $120 \mathrm{~min}$, corresponding to early 319 and late times post-induction when LTD is fully expressed. In concurrence with previous data 320 (Snyder et al, 2001), chemical mGluR-LTD (mGluR-LTD hereafter) decreased the surface 321 abundance of the GluA1 subunit of AMPARs (surface GluA1 puncta per cell, fold steady state: 322 mean \pm SE, steady state $1.0 \pm 10.039 n=13$, vehicle $0.97 \pm 0.052 n=13$, DHPG $0.81 \pm 0.051$ $323 \mathrm{n}=11$, vehicle vs. DHPG $p=0.019$, ANOVA with Tukey's post-test) attesting to the effectiveness 324 of the LTD protocol. We found that mGluR-LTD resulted in a net decrease in the overall density 325 of dendritic spines at 30 min post-treatment (total protrusions/10 $\mu \mathrm{m}$, mean $\pm S D$ vehicle $3.7 \pm 1.1$ $326 \mathrm{n}=54$ dendritic branches vs. mGluR-LTD $2.7 \pm 0.76 \mathrm{n}=78$ from $\mathrm{N}=30$ neurons per group; $p<0.001$, 327 Mann-Whitney test). Categorization of spines based on established morphological criteria 328 indicated that mGluR-LTD produced net loss of the synaptically stronger mushroom spines 329 whereas the density of thin spines was unaffected (Fig. 1E,F).

331 The finding that mGluR-LTD is impaired in Synpo ${ }^{-/-}$mice suggests that spines containing Synpo 332 are a primary locus of the plasticity. Therefore we next tested whether the observed net loss of 333 mushroom spines induced by mGluR-LTD might arise from elimination of spines containing 334 Synpo. Visualization of endogenous Synpo by immunolabeling of neurons filled with DilC $_{18}$ 335 shows that, as in the hippocampus where $\sim 10 \%$ of total spines contain Synpo/SA, in primary 336 hippocampal neurons $\sim 13 \%$ of all dendritic protrusions contain Synpo (mean $\pm S D, 13 \pm 4.6 \%$ $337 \mathrm{n}=17$ ) accounting for $\sim 30 \%$ of mushroom spines (mean $\pm S D, 32 \pm 13 \% n=44$ ). Surprisingly, we 338 found that despite net loss of mushroom spines, the density of Synpo-containing spines did not 339 significantly differ after mGluR-LTD compared to control (Fig. $\mathbf{1 G , H}$ ) so that the relative 340 frequency of Synpo-positive vs. total mushroom spines was modestly increased by mGluR-LTD 341 (Fig. 1I). Both mGluR1 and mGluR5 contribute to induction of mGluR-LTD by DHPG but only 342 selective inhibition of mGluR1 was shown to revert LTD and AMPAR internalization (Volk et al, 
343 2006) suggesting distinct receptor functions. To test whether both mGluR1 and mGluR5 play a

344 role in net loss of Synpo-lacking mushroom spines, mGluR-LTD was induced in the presence of

345 either Bay 36-7620 (Bay; $10 \mu \mathrm{M}$ ) or 2-Methyl-6-(phenylethynyl) pyridine (MPEP; $10 \mu \mathrm{M}$ ),

346 selective inverse agonists for mGluR1 and mGluR5, respectively. We found that whereas Bay

347 halted mGluR-LTD-induced net loss of mushroom spines (Fig. 2A,B), MPEP had no significant

348 effect (Fig. 2C,D). Collectively, these findings indicate that mGluR-LTD induces selective loss of

349 mushroom spines that do not contain Synpo whereas those in which Synpo/SA is present are

350 spared, a process that is dependent on mGluR1 activation during mGluR-LTD.

mGluR-LTD induces compartment-specific degradation of Synpo

Thus far our findings indicate that the proportion of mature mushroom spines tagged by Synpo remains constant in response to mGluR-LTD, suggesting that overall only mushroom spines in which Synpo is absent are lost. Hence whereas spines tagged by Synpo and SA remain stable, those 'untagged' are eliminated. If so, how can Synpo 'tagging' be restricted to subsets of spines? One possibility is that Synpo expression and availability for recruitment to spines could be constrained. In addition to being localized in spines, Synpo is present in dendritic shafts where it appears in discrete clusters and occasional tubule-like structures (Konietzny et al, 2019)(Deller et al, 2000). Various synaptic activity patterns were previously shown to regulate Synpo expression, including LTP (Yamazaki et al, 2001) and denervation-induced synaptic strengthening (Vlachos et al, 2013) that increase Synpo biosynthesis or enlargement of Synpo clusters, respectively. Homeostatic synaptic downscaling (Dörrbaum et al, 2020) in elevated activity induces instead a decrease in Synpo abundance.

Next we examined the impact of mGluR-LTD on Synpo expression using immunofluorescence in hippocampal neurons to visualize dendritic Synpo clusters and immunoblot in cortical neurons to monitor changes in Synpo abundance. In dendrites visualized by MAP2, mGluR-LTD reduced the density of Synpo clusters per cell within $30 \mathrm{~min}$ of stimulation, an effect that persisted at 120 min post-DHPG (Fig. $3 A, B$ ). In line with results by immunofluorescence, the total abundance of

372 Synpo protein was similarly reduced in cortical neurons after mGluR-LTD (Fig. 3C,D). We next

373 tested if both mGluR1 and mGluR5 contributed to the loss of dendritic Synpo by inducing 374 mGluR-LTD in the presence of either Bay or MPEP, respectively. In the presence of Bay, 375 mGluR-LTD failed to decrease Synpo clusters whereas Bay alone had no significant effect (Fig. $3763 E, F)$. In contrast, in the presence of MPEP, mGluR-LTD effectively reduced dendritic Synpo 
clusters and application of MPEP alone caused a modest decrease in Synpo (Fig. 3G,H). We reasoned that the effect of MPEP may be linked to an ability of mGluR5 to promote Synpo synthesis, potentially via signaling to mTOR (Richter \& Klann, 2009). We therefore examined

380 Synpo expression and turnover in neurons treated with the mTOR inhibitor rapamycin (Fig.

$\mathbf{4 A}, \mathbf{B}$ ) or the protein synthesis inhibitor cycloheximide, respectively (Fig. $\mathbf{4 C}-\boldsymbol{F}$ ). We found that

382 Synpo abundance decreased under both conditions, suggesting that constitutive basal

383 biosynthesis of Synpo is mTOR-dependent (Dörrbaum et al, 2020). Together, these findings

384 indicate that Synpo undergoes constitutive turnover and that mGluR1 activation during mGluR-

385 LTD produces a rapid, selective decrease of Synpo protein present in dendritic shafts.

mGluR-LTD promotes Synpo degradation via lysosomal proteolysis

Synpo is a natively unfolded protein (Chalovich \& Schroeter, 2010), the primary structure of which includes proline-rich regions that mark unstable proteins. Natively unfolded proteins tend to form aggregates that can be cleared via autophagy through lysosomal digestion (Lamark \& Johansen, 2012). To test if lysosomal proteolysis contributes to Synpo turnover, hippocampal neurons were treated with leupeptin (Leu; $200 \mu \mathrm{M}$ ) - an inhibitor of lysosomal cysteine, serine and threonine peptidases - for either $30 \mathrm{~min}$ or $120 \mathrm{~min}$. In these conditions, the density of Synpo clusters was not significantly altered after $30 \mathrm{~min}$ but increased over $120 \mathrm{~min}$ (Fig. 5A,B) concordant with a leupeptin-dependent increase in total Synpo in cortical neurons (Fig. 5C,D). Induction of mGluR-LTD in the presence of leupeptin failed to reduce the number of dendritic Synpo clusters (30 min and $120 \mathrm{~min}$; Fig. 5A,B) and to decrease total Synpo protein abundance (Fig. 5C,D). To confirm a role of lysosomal proteolysis in this process, we used Bafilomycin $A_{1}$ $400 \quad\left(\right.$ Baf $\left._{1} ; 100 \mathrm{nM}\right)$, a V-ATPase inhibitor that prevents lysosome acidification and blocks 401 autophagosome-lysosome fusion (Mauvezin et al, 2015). In the presence of Baf $A_{1}$, mGluR-LTD 402 failed to decrease dendritic Synpo (Fig. 5E,F) but did produce a modest enlargement of 403 individual Synpo clusters compared to vehicle or mGluR-LTD alone (Fig. 5G), suggesting 404 accumulation of Synpo in disabled lysosomes.

406 Next, we tested if the proteasome could also participate to DHPG-induced Synpo degradation 407 since proteasome activity was shown to contribute to protein turnover during mGluR-LTD (Citri 408 et al, 2009; Hou et al, 2006; Klein et al, 2015) and homeostatic down-scaling (Dörrbaum et al, 409 2020). Treatment of hippocampal neurons with the proteasome inhibitor MG132 (10 $\mu$ M, 30 $410 \mathrm{~min}$ ) produced a modest (not statistically significant) increase in the density of dendritic Synpo 
411 but did not block mGluR-LTD-induced loss of Synpo clusters (Fig. $\mathbf{5 H}, \mathbf{I}$ ). Similarly, incubation

412 with MG132 increased total Synpo abundance in cortical neurons but did not prevent mGluR-

413 LTD-induced degradation (Fig. 5J,K) suggesting that although Synpo turnover is partly

414 mediated by the proteasome, its degradation by mGluR-LTD is proteasome-independent.

415 Altogether, these results indicate that mGluR-LTD induces rapid degradation of dendritic Synpo

416 via the lysosomal pathway.

mGluR1 contributes to Synpo stabilization in dendritic spines

Our findings indicate that mGluR-LTD, primarily through activation of mGluR1, triggers selective degradation of Synpo present in dendritic shafts but not of Synpo targeted to spines that are spared by mGluR-LTD-dependent elimination. These observations raise the question of how Synpo could be stabilized and shielded from degradation in spines. Synpo, an actin-bundling protein, is recruited to spines through association with a-actinins (Asanuma et al, 2005; Kremerskothen et al, 2005), including a-actinin-4, which directly binds mGluR1 and is preferentially enriched in large spine heads (Kalinowska et al, 2015). We reasoned that Synpo might be physically tethered to mGluR1 via a multivalent complex contributing to its stabilization in spines. Co-immunoprecipitation assays show that anti-mGluR1 pulls down Synpo from brain cortex extracts of adult WT mice (Fig. 6A) whereas by immunolabeling mGluR1 can be detected in close apposition with Synpo in hippocampal neurons (Fig. 6B).

431 Synpo is retrieved in the postsynaptic density (PSD) fraction of excitatory synapses (Bayés et 432 al, 2012) and was shown to be linked to core scaffold proteins associated with the PSD (Li et al, 433 2017). To test whether mGluR1 contributes to Synpo stabilization at excitatory spine synapses, 434 we used mGluR1 knockout mice $\left(\mathrm{Grm} 1^{\mathrm{KO}}\right)$ to probe Synpo association with the PSD in absence 435 of the receptor. Immunoprecipitation of Synpo from brain cortex of adult wild type littermates $436\left(\mathrm{Grm} 1^{\mathrm{WT}}\right)$ effectively retrieved PSD95, a core component of the PSD (Fig. 6C): in contrast, pull437 down of PSD95 with Synpo were decreased in $G r m 1^{\mathrm{KO}}$ mice (Fig. $6 C, D$ ) in absence of 438 significant alterations in the relative abundance of the proteins (mean \pm SE, Grm $1^{\mathrm{WT}}$ Synpo 2.2 $439 \pm 0.25, \mathrm{Grm} 1^{\mathrm{KO}} 1.7 \pm 0.21 \mathrm{~N}=3$ mice per group, $p=0.1897 ; \mathrm{Grm} 1^{\mathrm{WT}} \mathrm{PSD} 952.5 \pm 0.64, \mathrm{Grm} 1^{\mathrm{KO}}$ $4402.7 \pm 0.82 \mathrm{~N}=3, p=0.8641$, two-tailed unpaired t-test), suggesting defects in the recruitment or 441 retention of Synpo to spine synapses.

443 To examine if impaired association of Synpo with the PSD may be linked to spine abnormalities 444 in $\mathrm{Grm}^{\mathrm{KO}}$ mice, we used $\mathrm{DilC}_{18}$ labeling to visualize dendritic spines in brain cortex tissue 
445 sections from juvenile ( 1.5-month old) and adult ( 7 to 12 -month old) $G m r 1^{\mathrm{KO}}$ and $\mathrm{Grm} 1^{\mathrm{WT}}$

446 littermates. We found that in $\mathrm{Grm} 1^{\mathrm{KO}}$ mice, the density of large mushroom spines was

447 significantly reduced compared to WT littermates (Fig. 7A,B): moreover, the heads of remaining

448 mushroom spines in $\mathrm{Grm} 1^{\mathrm{KO}}$ mice were significantly smaller compared to Grm $1^{\mathrm{WT}}$ littermates

449 (Fig. 7A,C). Collectively, our findings indicate that, when activated during mGluR-LTD, mGluR1

450 promotes Synpo degradation in dendrites whereas it locally supports Synpo stabilization in

451 spines, possibly through formation of a multivalent protein assembly.

\section{Discussion}

We report that mGluR-LTD is compromised in mice lacking Synpo/SA. Interestingly, it was previously shown that in Synpo ${ }^{\mathrm{KO}}$ mice basal neurotransmission is unaffected (Deller et al, 2003) and NMDAR-dependent LTD proceeds normally (Zhang et al, 2013). Unlike NMDARdependent LTD, mGluR-LTD requires rapid protein synthesis (Huber et al, 2000). Polyribosomes are present in proximity to the SA (Ostroff et al, 2010; Spacek \& Harris, 1997) which was proposed to function as satellite secretory station based on the presence of proteins of the secretory pathway within the SA (Pierce et al, 2001). Thus spines containing Synpo/SA

462 may enable local biosynthesis of proteins that support induction and expression of mGluR-LTD.

463 Other forms of synaptic plasticity were shown to be impaired in Synpo ${ }^{\mathrm{KO}}$ mice, including LTP 464 (Deller et al, 2003; Jedlicka et al, 2009; Zhang et al, 2013) and homeostatic potentiation 465 (Vlachos et al, 2013), congruent with observations that dendritic spines of Synpo ${ }^{\mathrm{KO}}$ mice do not undergo structural expansion during potentiation (Korkotian et al, 2014; Vlachos et al, 2009), which in turn requires protein synthesis (Yang et al, 2008).

Here we show that in hippocampal neurons, mGluR-LTD selectively reduces the overall density mature neurons in vitro, Synpo is targeted to spines with a frequency similar to that reported in vivo (Verbich et al, 2016). This is in line with findings that the diversity of excitatory synapses of 473 varying strength observed in vivo is recapitulated in neurons in vitro without prior history of 474 activity, implicating cell-intrinsic mechanisms in the generation of spine diversity (Hazan \& Ziv, 475 2020). Spines containing sER, and presumably Synpo, possess higher synaptic strength 476 (Holbro et al, 2009). Moreover spines harboring Synpo undergo slower constitutive turnover and 477 as such are more stable compared to mushroom spines in which Synpo is absent (Yap et al, 
2020). By analogy, in the preparation used here, mGluR-LTD appears to promote loss of spines that are 'weaker' and 'unstable' vs. strong and stable Synpo-positive spines that harbor the SA.

The impact of mGluR-LTD on spine shrinkage/elimination is controversial. Inhibition of Gp1

482 mGluRs was shown to limit the shrinkage of large spines induced by low-frequency glutamate 483 uncaging (Oh et al, 2013). In addition, chemical mGluR-LTD was shown to promote shrinkage 484 and long-lasting spine elimination in hippocampal CA1 pyramidal neurons (Ramiro-Cortés \& 485 Israely, 2013). Both findings supported the view that mGluR-LTD produces changes in spine 486 structural plasticity but a recent study failed to observe such changes during DHPG-LTD using 487 similar experimental strategies (Thomazeau et al, 2020). Although the reasons for the discrepancy remain unclear, our observations reveal a previously unappreciated complex function of mGluR-LTD in the elimination of selected spines distinguished by their molecular composition, an event that cannot be captured by examination of morphology and/or dimensions alone.

Synpo expression is developmentally regulated and is modified by activity patterns that produce plasticity, including LTP and homeostatic synaptic scaling. Here we find that mGluR-LTD triggers Synpo degradation via activation of mGluR1. While the function of Gp1 mGluRs in promoting protein synthesis is extensively documented (Osterweil et al, 2010; van Gelder et al, 2020), their role in proteolysis is not fully understood. Gp1 mGluRs are known to regulate the expression of Fragile $X$ Mental Retardation Protein (FMRP) by stimulating both its rapid proteasome-dependent degradation and synthesis (Hou et al, 2006; Nalavadi et al, 2012; Zhao et al, 2011). Furthermore, although proteasome-dependent and -independent proteolysis is critical for mGluR-LTD (Citri et al, 2009; Zhu et al, 2017), the identity of the substrates and

502 impact of their degradation are largely unknown. We propose that mGluR-LTD shunts Synpo 503 degradation to the lysosomal pathway that patrols dendrites and disposes of proteins 504 aggregates. Degradation of dendritic Synpo may deplete a protein 'reservoir' otherwise 505 available for recruitment to spines. sER tubules invade and retract from spines (Perez-Alvarez 506 et al, 2020; Wagner et al, 2011) and, although untested, dendritic Synpo associated with sER

507 could be co-recruited to spines. A potential scenario is that by reducing dendritic Synpo 508 availability, mGluR-LTD may exert the dual function of eliminating 'unstable' spines and limit 509 spurious spine strengthening by de novo recruitment of Synpo. 
511 We find that mGluR1 is critical for controlling both the abundance of Synpo in dendritic shafts

512 and Synpo maintenance at excitatory spine synapses, potentially via stabilization through

513 formation of a multivalent macromolecular complex. In support of this view, we show evidence

514 that in mice lacking mGluR1, Synpo recruitment/stabilization at excitatory synapses is impaired

515 as indicated by its diminished association with the PSD. Consistent with this possibility, we

516 provide the first report of profound spine dysmorphogenesis in Grm $1^{\mathrm{KO}}$ mice: in the mutants, we

517 observed a significant reduction of mushroom spines - in both adult and juvenile mice - that also

518 display smaller heads compared to WT littermates. Conceptually, the impact of mGluR1 both in

519 vivo and in the in vitro neuronal network is reminiscent of what observed in circuits in the

520 cerebellum at CF-PC synapses (Hashimoto \& Kano, 2013) and adult dLGN (Narushima et al,

521 2016) in which mGluR1 promotes stabilization of strong synaptic connections and elimination of

522 weaker inputs. Overall our results identify spines with Synaptopodin/ SA as the locus of mGluR-

523 LTD and underscore the importance of the molecular anatomy of spines in synaptic plasticity.

525 Author contributions: L.S.: designed research, performed research, analyzed data; Y.I.:

526 performed research, analyzed data; C.DS: performed research, analyzed data; P.Y.W.:

527 performed research, analyzed data; M.K.: performed research, analyzed data; R.A.M: designed

528 research, analyzed data, wrote the paper; A.F.: designed research, analyzed data, wrote the

529 paper.

\section{References}

533 Asanuma K, Kim K, Oh J, Giardino L, Chabanis S, Faul C, Reiser J, Mundel P (2005)

534 Synaptopodin regulates the actin-bundling activity of alpha-actinin in an isoform-specific

535 manner. The Journal of clinical investigation 115: 1188-1198

Bayés A, Collins MO, Croning MD, van de Lagemaat LN, Choudhary JS, Grant SG (2012) Comparative study of human and mouse postsynaptic proteomes finds high compositional conservation and abundance differences for key synaptic proteins. PloS one 7: e46683

$$
\text { Berry KP, Nedivi E (2017) Spine Dynamics: Are They All the Same? Neuron 96: 43-55 }
$$

Chalovich JM, Schroeter MM (2010) Synaptopodin family of natively unfolded, actin binding proteins: physical properties and potential biological functions. Biophysical reviews 2: 181-189

Cheng C, Trzcinski O, Doering LC (2014) Fluorescent labeling of dendritic spines in cell cultures with the carbocyanine dye "Dil". Frontiers in neuroanatomy 8: 30

Cingolani LA, Goda Y (2008) Actin in action: the interplay between the actin cytoskeleton and 550 synaptic efficacy. Nature reviews Neuroscience 9: 344-356 
Citri A, Soler-Llavina G, Bhattacharyya S, Malenka RC (2009) N-methyl-D-aspartate receptorand metabotropic glutamate receptor-dependent long-term depression are differentially regulated by the ubiquitin-proteasome system. The European journal of neuroscience 30: 14431450

Cooke SK, Russin J, Moulton K, Nadel J, Loutaev I, Gu Q, Li Z, Smith CB (2019) Effects of the presence and absence of amino acids on translation, signaling, and long-term depression in hippocampal slices from Fmr1 knockout mice. Journal of neurochemistry 151: 764-776

Czarnecki K, Haas CA, Bas Orth C, Deller T, Frotscher M (2005) Postnatal development of synaptopodin expression in the rodent hippocampus. The Journal of comparative neurology 490: $133-144$

Deller T, Korte M, Chabanis S, Drakew A, Schwegler H, Stefani GG, Zuniga A, Schwarz K, apparatus and show deficits in synaptic plasticity. Proceedings of the National Academy of Sciences of the United States of America 100: 10494-10499

Deller T, Mundel P, Frotscher M (2000) Potential role of synaptopodin in spine motility by coupling actin to the spine apparatus. Hippocampus 10: 569-581

Dörrbaum AR, Alvarez-Castelao B, Nassim-Assir B, Langer JD, Schuman EM (2020) Proteome dynamics during homeostatic scaling in cultured neurons. eLife 9

Fifková E, Markham JA, Delay RJ (1983) Calcium in the spine apparatus of dendritic spines in the dentate molecular layer. Brain research 266: 163-168

Harris KM (2020) Structural LTP: from synaptogenesis to regulated synapse enlargement and clustering. Current opinion in neurobiology 63: 189-197

Harris KM, Jensen FE, Tsao B (1992) Three-dimensional structure of dendritic spines and synapses in rat hippocampus (CA1) at postnatal day 15 and adult ages: implications for the maturation of synaptic physiology and long-term potentiation. The Journal of neuroscience : the official journal of the Society for Neuroscience 12: 2685-2705

Hashimoto K, Kano M (2013) Synapse elimination in the developing cerebellum. Cellular and molecular life sciences : CMLS 70: 4667-4680

Hazan L, Ziv NE (2020) Activity Dependent and Independent Determinants of Synaptic Size Diversity. The Journal of neuroscience : the official journal of the Society for Neuroscience 40: 2828-2848

Ho J, Tumkaya T, Aryal S, Choi H, Claridge-Chang A (2019) Moving beyond P values: data analysis with estimation graphics. Nature methods 16: 565-566

Holbro N, Grunditz A, Oertner TG (2009) Differential distribution of endoplasmic reticulum controls metabotropic signaling and plasticity at hippocampal synapses. Proceedings of the 
601

602

603

604

605

606

607

608

609

610

611

612

613

614

615

616

617

618

619

620

621

622

623

624

625

626

627

628

629

630

631

632

633

634

635

636

637

638

639

640

641

642

643

644

645

646

647

648

649

650

Hou L, Antion MD, Hu D, Spencer CM, Paylor R, Klann E (2006) Dynamic translational and proteasomal regulation of fragile $\mathrm{X}$ mental retardation protein controls $\mathrm{mGluR}$-dependent longterm depression. Neuron 51: 441-454

Huber KM, Gallagher SM, Warren ST, Bear MF (2002) Altered synaptic plasticity in a mouse model of fragile X mental retardation. Proceedings of the National Academy of Sciences of the United States of America 99: 7746-7750

Huber KM, Kayser MS, Bear MF (2000) Role for rapid dendritic protein synthesis in hippocampal mGluR-dependent long-term depression. Science (New York, NY) 288: 1254-1257

Jedlicka P, Schwarzacher SW, Winkels R, Kienzler F, Frotscher M, Bramham CR, Schultz C, Bas Orth C, Deller T (2009) Impairment of in vivo theta-burst long-term potentiation and network excitability in the dentate gyrus of synaptopodin-deficient mice lacking the spine apparatus and the cisternal organelle. Hippocampus 19: 130-140

Kalinowska M, Chávez AE, Lutzu S, Castillo PE, Bukauskas FF, Francesconi A (2015) Actinin-4 Governs Dendritic Spine Dynamics and Promotes Their Remodeling by Metabotropic Glutamate Receptors. The Journal of biological chemistry 290: 15909-15920

Klein ME, Castillo PE, Jordan BA (2015) Coordination between Translation and Degradation Regulates Inducibility of mGluR-LTD. Cell reports 10: 1459-1466

Konietzny A, González-Gallego J, Bär J, Perez-Alvarez A, Drakew A, Demmers JAA, Dekkers DHW, Hammer JA, 3rd, Frotscher M, Oertner TG, Wagner W, Kneussel M, Mikhaylova M (2019) Myosin V regulates synaptopodin clustering and localization in the dendrites of hippocampal neurons. Journal of cell science 132

Korkotian E, Frotscher M, Segal M (2014) Synaptopodin regulates spine plasticity: mediation by calcium stores. The Journal of neuroscience : the official journal of the Society for Neuroscience 34: $11641-11651$

Kremerskothen J, Plaas C, Kindler S, Frotscher M, Barnekow A (2005) Synaptopodin, a molecule involved in the formation of the dendritic spine apparatus, is a dual actin/alpha-actinin binding protein. Journal of neurochemistry 92: 597-606

Lamark T, Johansen T (2012) Aggrephagy: selective disposal of protein aggregates by macroautophagy. International journal of cell biology 2012: 736905

Li J, Zhang W, Yang H, Howrigan DP, Wilkinson B, Souaiaia T, Evgrafov OV, Genovese G, Clementel VA, Tudor JC, Abel T, Knowles JA, Neale BM, Wang K, Sun F, Coba MP (2017) Spatiotemporal profile of postsynaptic interactomes integrates components of complex brain disorders. Nature neuroscience 20: 1150-1161

Lüscher C, Huber KM (2010) Group 1 mGluR-dependent synaptic long-term depression: mechanisms and implications for circuitry and disease. Neuron 65: 445-459

Mauvezin C, Nagy P, Juhász G, Neufeld TP (2015) Autophagosome-lysosome fusion is independent of V-ATPase-mediated acidification. Nature communications 6: 7007 
McKinney RA (2010) Excitatory amino acid involvement in dendritic spine formation, maintenance and remodelling. The Journal of physiology 588: 107-116 Schierberl KC, Pagiazitis JG, Mendelsohn AI, Francesconi A, Edwards RH, Milner TA, Rajadhyaksha AM, van Roessel PJ, Mentis GZ, Kaltschmidt JA (2016) Sensory-Derived Glutamate Regulates Presynaptic Inhibitory Terminals in Mouse Spinal Cord. Neuron 90: 11891202

Nalavadi VC, Muddashetty RS, Gross C, Bassell GJ (2012) Dephosphorylation-induced ubiquitination and degradation of FMRP in dendrites: a role in immediate early mGluRstimulated translation. The Journal of neuroscience : the official journal of the Society for Neuroscience 32: 2582-2587

Narushima M, Uchigashima M, Yagasaki Y, Harada T, Nagumo Y, Uesaka N, Hashimoto K, Aiba A, Watanabe M, Miyata M, Kano M (2016) The Metabotropic Glutamate Receptor Subtype 1 Mediates Experience-Dependent Maintenance of Mature Synaptic Connectivity in the Visual Thalamus. Neuron 91: 1097-1109

Oh WC, Hill TC, Zito K (2013) Synapse-specific and size-dependent mechanisms of spine structural plasticity accompanying synaptic weakening. Proceedings of the National Academy of Sciences of the United States of America 110: E305-312

Oh WC, Parajuli LK, Zito K (2015) Heterosynaptic structural plasticity on local dendritic segments of hippocampal CA1 neurons. Cell reports 10: 162-169

Osterweil EK, Krueger DD, Reinhold K, Bear MF (2010) Hypersensitivity to mGluR5 and ERK1/2 leads to excessive protein synthesis in the hippocampus of a mouse model of fragile $X$ syndrome. The Journal of neuroscience : the official journal of the Society for Neuroscience 30: 15616-15627

Ostroff LE, Cain CK, Bedont J, Monfils MH, Ledoux JE (2010) Fear and safety learning differentially affect synapse size and dendritic translation in the lateral amygdala. Proceedings of the National Academy of Sciences of the United States of America 107: 9418-9423

Perez-Alvarez A, Yin S, Schulze C, Hammer JA, Wagner W, Oertner TG (2020) Endoplasmic reticulum visits highly active spines and prevents runaway potentiation of synapses. Nature communications 11: 5083

Pierce JP, Mayer T, McCarthy JB (2001) Evidence for a satellite secretory pathway in neuronal dendritic spines. Current biology : $C B$ 11: 351-355

Ramiro-Cortés Y, Israely I (2013) Long lasting protein synthesis- and activity-dependent spine shrinkage and elimination after synaptic depression. PloS one 8: e71155

Richter JD, Klann E (2009) Making synaptic plasticity and memory last: mechanisms of translational regulation. Genes \& development 23: 1-11

Roelandse M, Matus A (2004) Hypothermia-associated loss of dendritic spines. The Journal of neuroscience : the official journal of the Society for Neuroscience 24: 7843-7847 
702

703

704

705

706

707

708

709

710

711

712

713

714

715

716

717

718

719

720

721

722

723

724

725

726

727

728

729

730

731

732

733

734

735

736

737

738

739

740

741

742

743

744

745

746

747

748

749

750

751

Sahin M, Sur M (2015) Genes, circuits, and precision therapies for autism and related neurodevelopmental disorders. Science (New York, NY) 350

Schindelin J, Arganda-Carreras I, Frise E, Kaynig V, Longair M, Pietzsch T, Preibisch S, Rueden C, Saalfeld S, Schmid B, Tinevez JY, White DJ, Hartenstein V, Eliceiri K, Tomancak P, Cardona A (2012) Fiji: an open-source platform for biological-image analysis. Nature methods 9: $676-682$

Snyder EM, Philpot BD, Huber KM, Dong X, Fallon JR, Bear MF (2001) Internalization of ionotropic glutamate receptors in response to mGluR activation. Nature neuroscience 4: 10791085

Spacek J (1985) Three-dimensional analysis of dendritic spines. II. Spine apparatus and other cytoplasmic components. Anatomy and embryology 171: 235-243

Spacek J, Harris KM (1997) Three-dimensional organization of smooth endoplasmic reticulum in hippocampal CA1 dendrites and dendritic spines of the immature and mature rat. The Journal of neuroscience : the official journal of the Society for Neuroscience 17: 190-203

Stein IS, Zito K (2019) Dendritic Spine Elimination: Molecular Mechanisms and Implications. The Neuroscientist : a review journal bringing neurobiology, neurology and psychiatry 25: 27-47

Thomazeau A, Bosch M, Essayan-Perez S, Barnes SA, De Jesus-Cortes H, Bear MF (2020) Dissociation of functional and structural plasticity of dendritic spines during NMDAR and mGluRdependent long-term synaptic depression in wild-type and fragile X model mice. Molecular psychiatry

van Gelder C, Penning R, Veth TS, Catsburg LAE, Hoogenraad CC, MacGillavry HD, Altelaar M (2020) Temporal Quantitative Proteomics of mGluR-induced Protein Translation and Phosphorylation in Neurons. Molecular \& cellular proteomics : MCP 19: 1952-1967

Verbich D, Becker D, Vlachos A, Mundel P, Deller T, McKinney RA (2016) Rewiring neuronal microcircuits of the brain via spine head protrusions--a role for synaptopodin and intracellular calcium stores. Acta neuropathologica communications 4: 38

Vlachos A, Ikenberg B, Lenz M, Becker D, Reifenberg K, Bas-Orth C, Deller T (2013) Synaptopodin regulates denervation-induced homeostatic synaptic plasticity. Proceedings of the National Academy of Sciences of the United States of America 110: 8242-8247

Vlachos A, Korkotian E, Schonfeld E, Copanaki E, Deller T, Segal M (2009) Synaptopodin regulates plasticity of dendritic spines in hippocampal neurons. The Journal of neuroscience : the official journal of the Society for Neuroscience 29: 1017-1033

Volk LJ, Daly CA, Huber KM (2006) Differential roles for group 1 mGluR subtypes in induction and expression of chemically induced hippocampal long-term depression. Journal of neurophysiology 95: 2427-2438

Wagner W, Brenowitz SD, Hammer JA, 3rd (2011) Myosin-Va transports the endoplasmic reticulum into the dendritic spines of Purkinje neurons. Nature cell biology 13: 40-48 
752

753

754

755

756

757

758

759

760

761

762

763

764

765

766

767

768

769

770

771

772

773

774

775

776

777

778

779

780

781

782

783

784

785

786

787

788

789
Wang XB, Yang Y, Zhou Q (2007) Independent expression of synaptic and morphological plasticity associated with long-term depression. The Journal of neuroscience : the official journal of the Society for Neuroscience 27: 12419-12429

Wiegert JS, Oertner TG (2013) Long-term depression triggers the selective elimination of weakly integrated synapses. Proceedings of the National Academy of Sciences of the United States of America 110: E4510-4519

Yamazaki M, Matsuo R, Fukazawa Y, Ozawa F, Inokuchi K (2001) Regulated expression of an actin-associated protein, synaptopodin, during long-term potentiation. Journal of neurochemistry 79: 192-199

Yang Y, Wang XB, Frerking M, Zhou Q (2008) Spine expansion and stabilization associated with long-term potentiation. The Journal of neuroscience : the official journal of the Society for Neuroscience 28: $5740-5751$

Yap K, Drakew A, Smilovic D, Rietsche M, Paul MH, Vuksic M, Del Turco D, Deller T (2020) The actin-modulating protein synaptopodin mediates long-term survival of dendritic spines. eLife 9

Zagrebelsky M, Holz A, Dechant G, Barde YA, Bonhoeffer T, Korte M (2005) The p75 neurotrophin receptor negatively modulates dendrite complexity and spine density in hippocampal neurons. The Journal of neuroscience : the official journal of the Society for Neuroscience 25: 9989-9999

Zhang XL, Pöschel B, Faul C, Upreti C, Stanton PK, Mundel P (2013) Essential role for synaptopodin in dendritic spine plasticity of the developing hippocampus. The Journal of neuroscience : the official journal of the Society for Neuroscience 33: 12510-12518

Zhao W, Chuang SC, Bianchi R, Wong RK (2011) Dual regulation of fragile X mental retardation protein by group I metabotropic glutamate receptors controls translation-dependent epileptogenesis in the hippocampus. The Journal of neuroscience : the official journal of the Society for Neuroscience 31: 725-734

Zhu G, Briz V, Seinfeld J, Liu Y, Bi X, Baudry M (2017) Calpain-1 deletion impairs mGluRdependent LTD and fear memory extinction. Scientific reports 7: 42788 

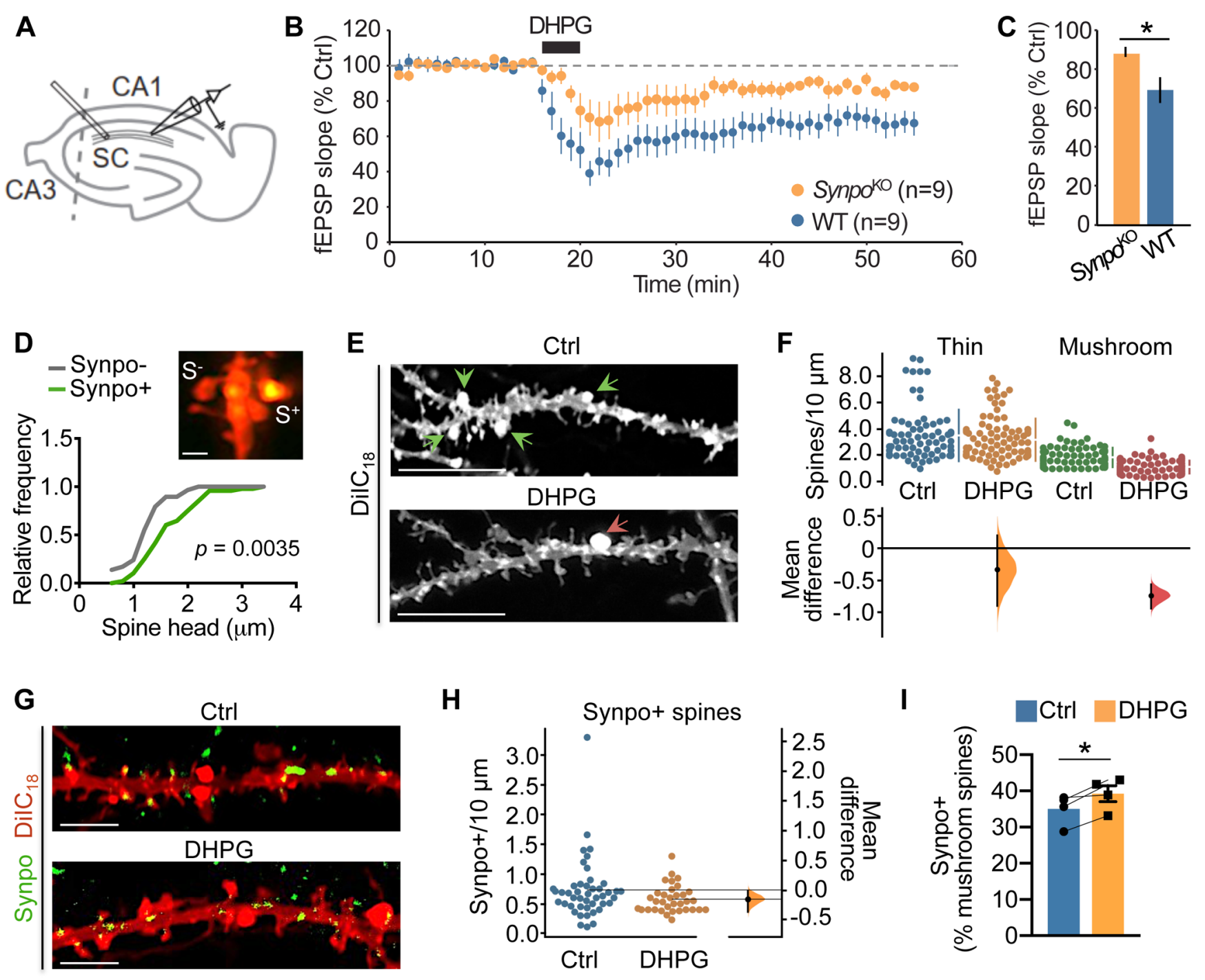

H
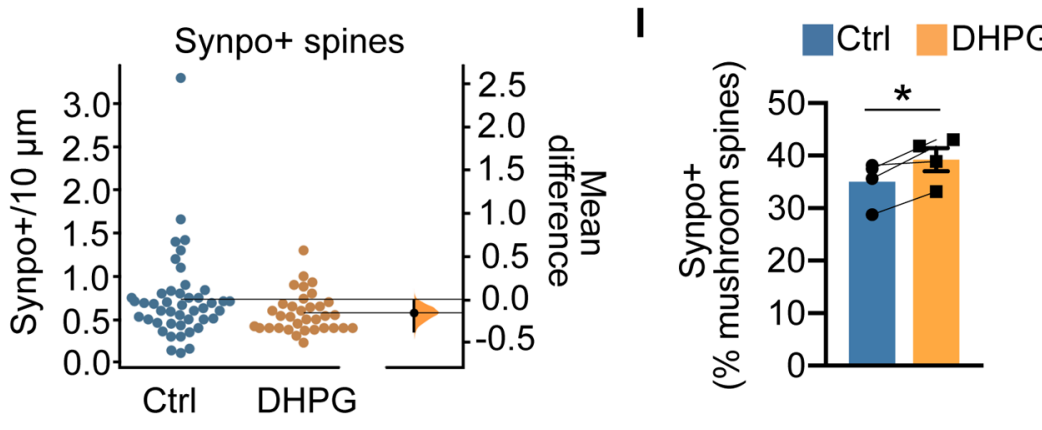

Figure 1. Spines with stable Synpo are spared from elimination and required for mGluR-LTD.

A. Illustration of the approximate locations of stimulating and recording electrodes in hippocampal slices to measure mGluR-LTD at Schaffer Collateral (SC) to CA1 synapses.

B. Time-course of synaptic changes induced by bath application of $100 \mu \mathrm{M}$ DHPG during 5 minutes in WT ( $n=9$ slices, $N=4$ mice) and Synpo ${ }^{\mathrm{KO}}$ mice ( $\mathrm{n}=9$ slices, $\mathrm{N}=5$ mice).

C. Quantification of average mGluR-LTD in the last 10 min of the recording: mean \pm SEM Synpo ${ }^{\mathrm{KO}} 87 \% \pm 3$, WT $69 \% \pm 6, \mathrm{n}=9$ slices, $p<0.05$, Mann-Whitney test.

D. Characterization of mushroom spines with or without Synpo. Representative image (Airyscan) of spines in hippocampal neurons labeled with $\mathrm{DilC}_{18}$ and anti-Synpo. S+, spines with Synpo, S-, spines without Synpo: scale bar $0.5 \mu \mathrm{m}$. Relative frequency distribution of spine head dimensions. Synpo- $(n=29)$, Synpo+ ( $n=48)$, Kolmogorov-Smirnov test.

E. Images of DilC $_{18}$-labeled neurons treated with vehicle (Ctrl) or mGluR-LTD (DHPG; 30 min recovery); arrowheads indicate mushroom spines. Scale bars $10 \mu \mathrm{m}$. 
F. Quantification of thin and mushroom spine density per $10 \mu \mathrm{m}$. Mean \pm SD, thin spines Ctrl $3.5 \pm 2.0$ ( $n=74$ dendritic branches), DHPG $3.2 \pm 1.6(n=91), N=36$ cells per group, $p=0.246$ two-sided permutation $t$-test; mushroom spines, Ctrl 1.9 $\pm 0.74(n=78)$, DHPG $1.1 \pm 0.50(n=109), N=45$ cells, $p<0.0001$. GardnerAltman estimation plot: mean difference (dot, bottom panel) is plotted on a floating axis as a bootstrap sampling distribution, vertical error bars indicate the $95 \%$ confidence interval.

G. Representative images of hippocampal neurons treated with vehicle (Ctrl) or DHPG (30 min recovery) and labeled with DilC $_{18}$ and anti-Synpo antibody; scale bars, $4 \mu \mathrm{m}$.

$H$. Quantification of Synpo+ spines in neurons treated with vehicle (Ctrl) or DHPG from images like those in (g); spines $/ 10 \mu \mathrm{m}$, mean $\pm \mathrm{SD}$, Ctrl $0.73 \pm 0.51(\mathrm{n}=45)$, DHPG $0.58 \pm 0.23(\mathrm{n}=34), \mathrm{N}=30$ cells per group, $p=0.096$ two-sided permutation t-test.

I. Percentage of Synpo+ spines relative to total mushroom spines in neurons treated with vehicle (Ctrl) or mGluR-LTD (30 min): mean \pm SE from $\mathrm{N}=4$ experiments, $p=0.04$, paired t-test. 

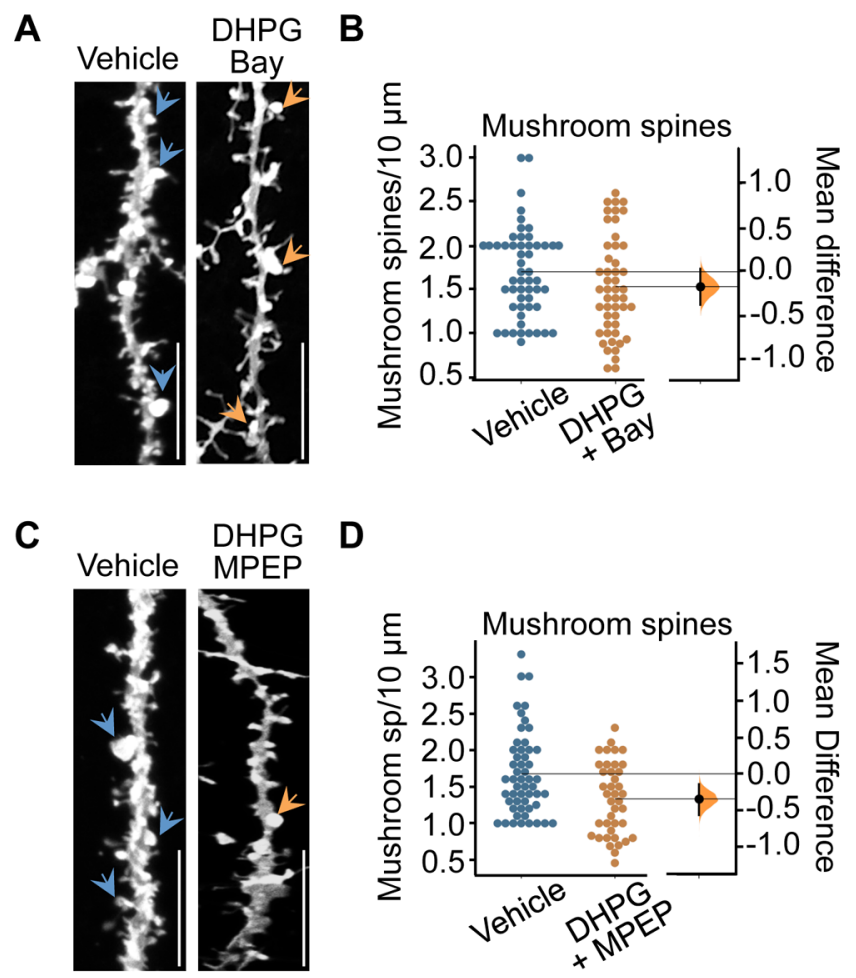

Figure 2. mGluR-LTD induces loss of mushroom spines through activation of mGluR1.

A. Representative images of hippocampal neurons treated with vehicle or DHPG in the presence of Bay (30 min recovery) and labeled with DilC $_{18}$; arrowheads indicate mushroom spines, scale bars, $10 \mu \mathrm{m}$.

B. Quantification of mushroom spine density from images like those in (a): mean \pm SD, vehicle $1.7 \pm 0.50$ $(\mathrm{n}=55)$, DHPG+Bay $1.5 \pm 0.57(\mathrm{n}=49), \mathrm{N}=25$ cells per group, $p=0.1044$, two-sided permutation $t$ test.

C. Representative images of hippocampal neurons treated with vehicle or DHPG in the presence of MPEP (30 min recovery) and labeled with DilC $_{18}$; scale bars, $10 \mu \mathrm{m}$.

D. Quantification of mushroom spine density from images like those in (c): mean \pm SD, vehicle $1.7 \pm 0.57$ $(n=53)$, DHPG+MPEP $1.3 \pm 0.49(n=40)$ from 3 experiments, $p=0.0032$, two-sided permutation $t$ test. 


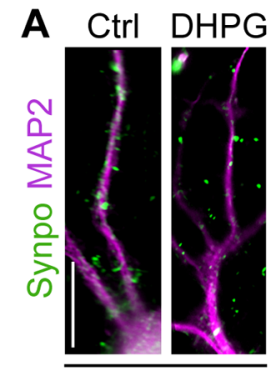

$30 \mathrm{~min}$

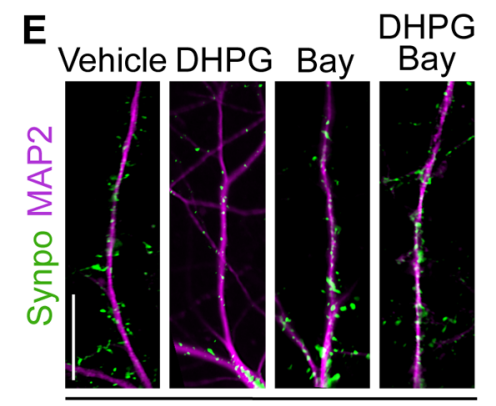

$30 \mathrm{~min}$

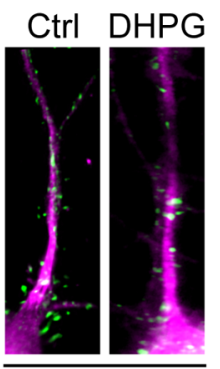

$120 \min$
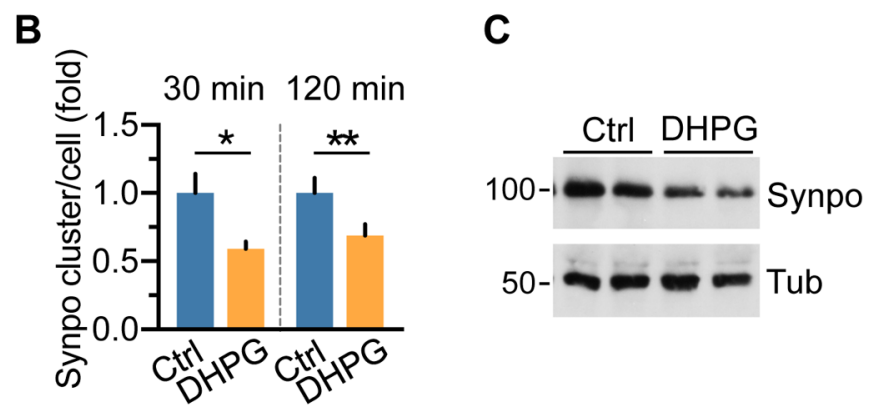

D

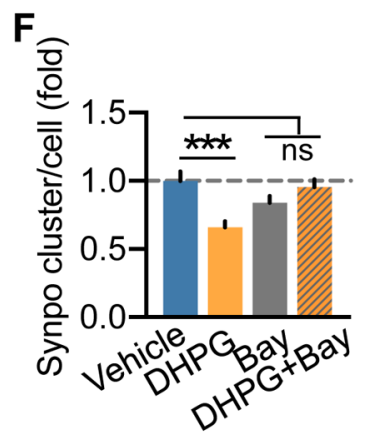

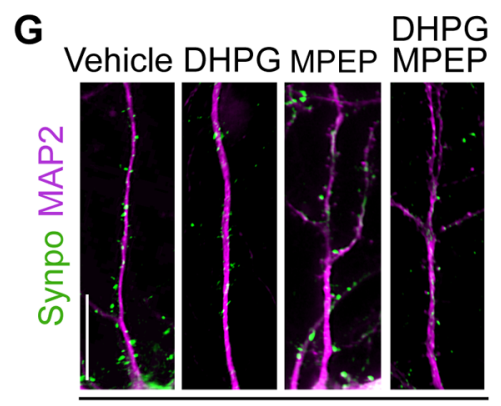

$30 \min$

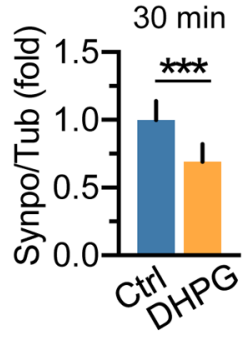

$\mathbf{H}$

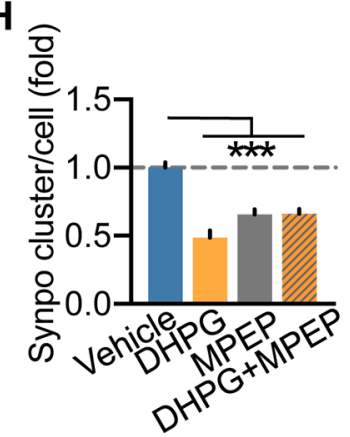

Figure 3. mGluR-LTD induces degradation of Synpo in dendritic shafts.

A. Representative images and quantification of immunolabeled Synpo in MAP2-positive dendrites of hippocampal neurons treated with vehicle (Ctrl) or DHPG followed by recovery for 30 or 120 min. Scale bars, $15 \mu \mathrm{m}$.

B. Quantification of dendritic Synpo clusters per cell (fold vehicle) from images like in (a): mean \pm SE 30 min, Ctrl $1.0 \pm 0.14$, DHPG $0.59 \pm 0.053, n=71$ cells per group from $\mathrm{N}=6$ experiments, $\left(^{*}\right) p=0.0106 ; 120$ min, Ctrl $1.0 \pm 0.111(\mathrm{n}=44)$, DHPG $\left.0.69 \pm 0.083(\mathrm{n}=45), \mathrm{N}=4,{ }^{* *}\right) p=0.004$, paired t-test.

C. Representative immunoblot of cortical neurons treated with vehicle (Ctrl) or DHPG followed by 30 min recovery: Tubulin (Tub), loading control.

D. Quantification of Synpo (fold Ctrl) from blots as in (c): mean \pm SE, Ctrl 1.0 \pm 0.14 , DHPG 0.69 $\pm 0.13, N=5$, $\left({ }^{* * *}\right) p=0.0002$, paired t-test.

E. Representative images of Synpo in hippocampal neurons treated with vehicle, Bay or DHPG (in presence/absence of Bay) followed by 30 min recovery. Scale bar $15 \mu \mathrm{m}$.

F. Quantification of Synpo clusters from images as in (e). Mean \pm SE, vehicle $1.0 \pm 0.069(n=17)$, DHPG 0.66 $\pm 0.044(n=28)$, Bay $0.84 \pm 0.049(n=26), D H P G+B a y 0.95 \pm 0.058(n=18)$ from 2 experiments, $\left({ }^{* * *}\right)$ $p<0.001$, (ns) $p>0.1$, ANOVA with Tukey's post-test.

G. Representative images of Synpo in hippocampal neurons treated with vehicle, MPEP or DHPG in presence/absence of MPEP followed by 30 min recovery. Scale bar $15 \mu \mathrm{m}$.

$H$. Quantification of Synpo clusters from images as in (g). Mean \pm SE, vehicle $1.0 \pm 0.039(n=29)$, DHPG 0.49 $\pm 0.052(n=16)$, MPEP $0.66 \pm 0.038(n=32)$, DHPG+MPEP $0.66 \pm 0.035(n=31)$; from 4 experiments, $\left({ }^{* * *}\right)$ $p<0.001$, ANOVA with Tukey's post-test. 


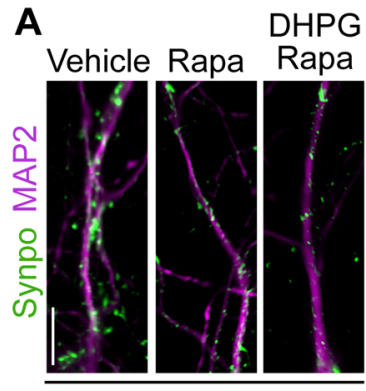

$30 \mathrm{~min}$

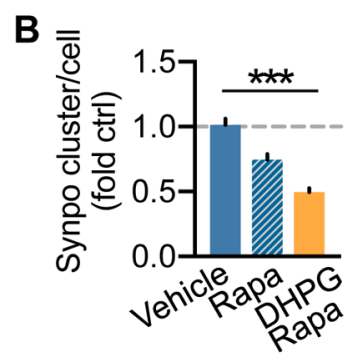

C

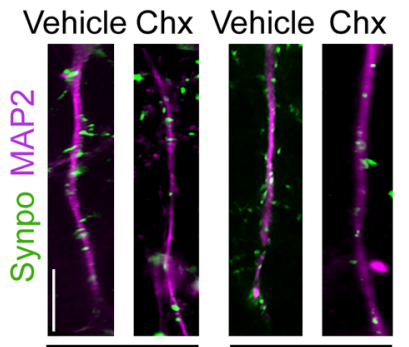

$120 \min$

D

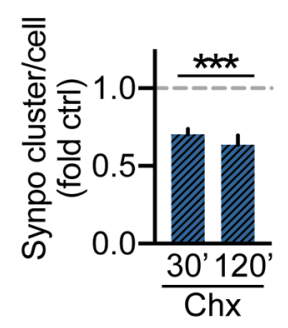

E
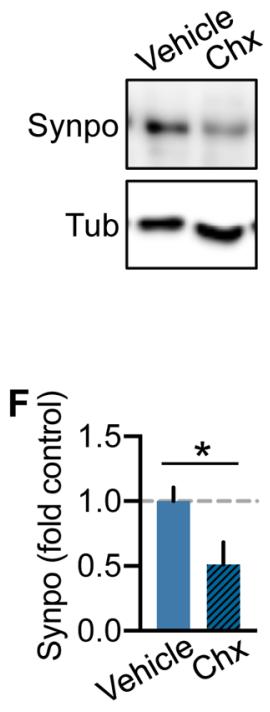

Figure 4. Basal expression of Synpo is regulated by mTOR and ongoing protein synthesis.

A. Representative images of immunolabeled Synpo in MAP2-positive dendrites of hippocampal neurons treated with vehicle, rapamycin $(20 \mathrm{nM})$ or DHPG in the presence of rapamycin (30 min recovery); scale bars, $10 \mu \mathrm{m}$.

B. Quantification of Synpo clusters per cell (fold control vehicle) from images as in (a). Mean \pm SE vehicle 1.0 $\pm 0.048(n=23)$, rapamycin $0.75 \pm 0.042(n=40)$, DHPG+rapamycin $0.50 \pm 0.031(n=30), 2$ experiments; $\left({ }^{* * *}\right) p<0.001$, ANOVA with Tukey's post-test.

C. Representative images of dendritic Synpo in hippocampal neurons treated with vehicle or Chx (50 $\mu \mathrm{M})$ for $30 \mathrm{~min}$ and $120 \mathrm{~min}$; scale bar $10 \mu \mathrm{m}$.

D. Quantification of Synpo clusters (fold vehicle) from images as in (b). Mean \pm SE 30 min, vehicle $1.0 \pm 0.032$ $(n=13)$, Chx $0.70 \pm 0.036(n=18) ; 120$ min vehicle $1.0 \pm 0.033(n=10)$, Chx $0.64 \pm 0.060(n=14)$, from 2 experiments, $\left({ }^{* * *}\right) p<0.001$, ANOVA with Tukey's post-test.

E. Representative immunoblot of cortical neurons treated with vehicle or Chx for $120 \mathrm{~min}$.

F. Quantification of total Synpo from blots as in (e): mean \pm SE, vehicle $1.0 \pm 0.11(n=5)$, Chx $0.51 \pm 0.17$ $(\mathrm{n}=5), 2$ experiments, $\left({ }^{*}\right) p=0.042$, two-tailed unpaired t-test. 


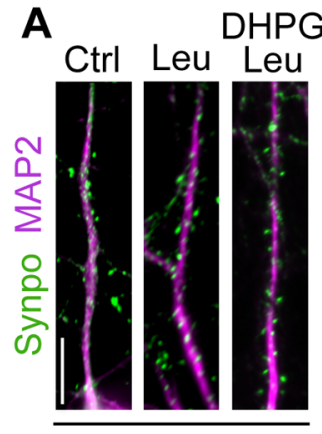

$30 \mathrm{~min}$

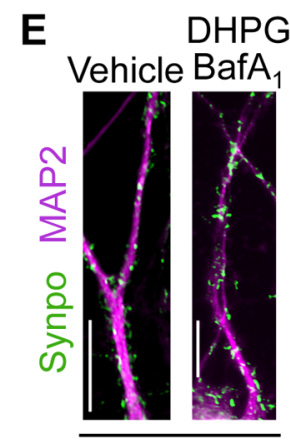

$30 \min$

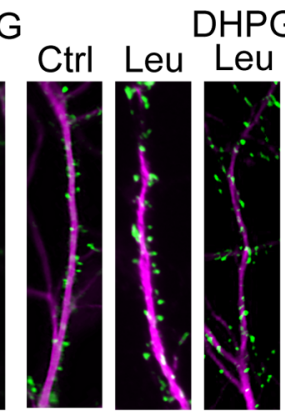

$120 \mathrm{~min}$

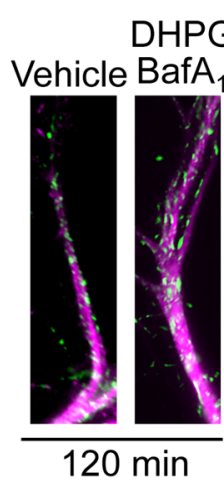

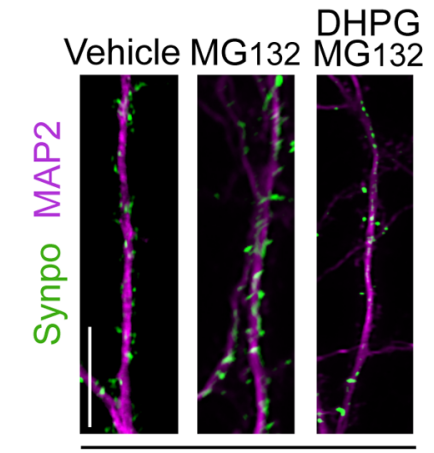

$30 \min$

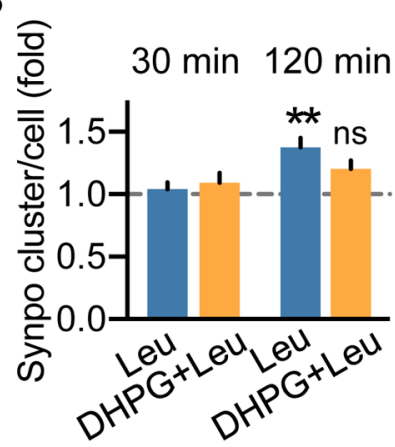

F

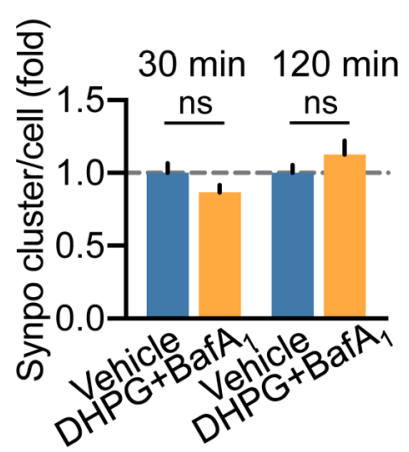

C

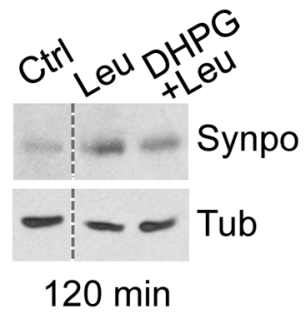

G

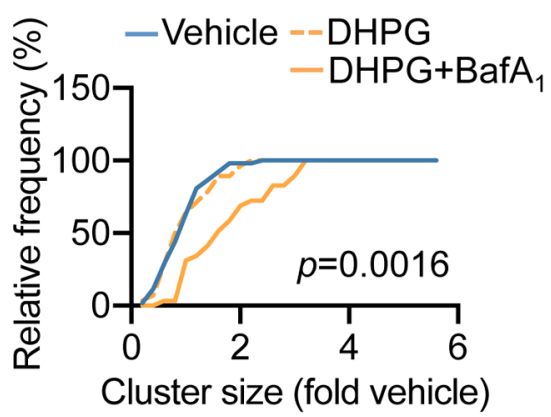

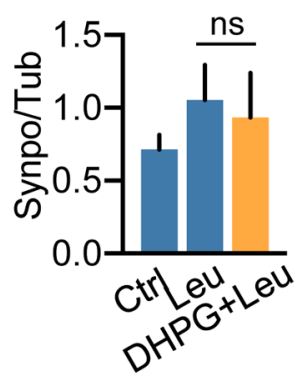
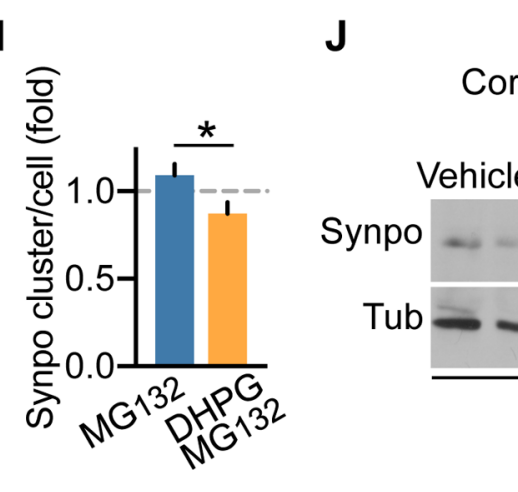

Cortical neurons:
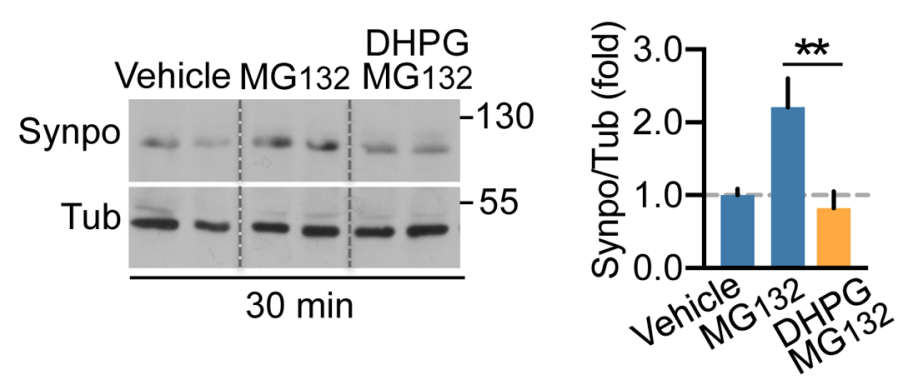

Figure 5. mGluR-LTD promotes Synpo degradation via lysosomal proteolysis.

A. Representative images of Synpo in hippocampal neurons treated with vehicle (Ctrl), leupeptin (Leu), DHPG in the presence/absence of leupeptin for 30 or $120 \mathrm{~min}$.

B. Quantification of Synpo clusters from images as in (a). Mean $\pm S E 30 \mathrm{~min}$, Ctrl $1.0 \pm 0.06(\mathrm{n}=30)$, Leu $1.04 \pm$ 0.054 ( $n=35)$, DHPG+Leu $1.1 \pm 0.079 ; 120 \mathrm{~min}$, Ctrl $1.0 \pm 0.076(n=19)$, Leu $1.4 \pm 0.076(n=36)$,

DHPG+Leu $1.2 \pm 0.07$ ( $n=26)$, 2 experiments; (ns) $p=0.22,\left({ }^{* *}\right) p=0.004$, ANOVA, Tukey's post-test.

C. Representative immunoblot of cortical neurons treated with vehicle (Ctrl), Leu, DHPG in the presence of Leu (120 min recovery); Tubulin (Tub), loading control.

D. Quantification of blots as in (c). Total Synpo (fold Tub): mean \pm SE, Ctrl 0.71 \pm 0.05 , Leu 1.1 \pm 0.12 , DHPG+Leu $0.93 \pm 0.15$, 4 independent determinations, (ns) $p=0.640$, two-tailed unpaired t-test.

E. Representative images of Synpo in hippocampal neurons treated with vehicle or DHPG in the presence of BafA1 for 30 or $120 \mathrm{~min}$; scale bar $15 \mu \mathrm{m}$. 
F. Quantification of Synpo clusters from images as in (e). Mean \pm SE 30 min, vehicle $1.0 \pm 0.066,(n=24)$, DHPG+BafA $10.87 \pm 0.049(\mathrm{n}=36), 2$ experiments, $(\mathrm{ns}) \mathrm{p}=0.41 ; 120 \mathrm{~min}$, vehicle $1.0 \pm 0.054,(\mathrm{n}=26)$, DHPG+BafA $1.13 \pm 0.095(n=20)$, (ns) $p=0.56$, ANOVA, Tukey's post-test.

G. Distribution of Synpo cluster size (fold vehicle) in cells treated with vehicle $(n=53)$ or DHPG (30 min recovery) in absence $(n=28)$ or presence of BafA $_{1}(n=29)$; Kolmogorov-Smirnov test.

H. Representative images of Synpo in neurons treated with vehicle, MG132, DHPG+MG132 followed by recovery in MG132 (30 min): scale bar $15 \mu \mathrm{m}$.

I. Quantification of Synpo clusters from images as in (h). Mean \pm SE, vehicle $1.0 \pm 0.083(n=20)$, MG132 1.1 $\pm 0.064(\mathrm{n}=27)$, DHPG+MG132 $0.87 \pm 0.064(\mathrm{n}=25), 2$ experiments, $\left.{ }^{*}\right) p=0.0196$, two-tailed unpaired $t-$ test.

J. Representative blot of cortical neurons treated with vehicle, MG132, DHPG+MG132 with recovery in the presence of MG132.

K. Quantification of Synpo from blots as in (j): mean \pm SE, vehicle $1.0 \pm 0.088(n=10)$, MG132 $2.2 \pm 0.39$ $(\mathrm{n}=5)$, DHPG+MG132 $0.82 \pm 0.23(\mathrm{n}=7), 3$ experiments, $\left({ }^{* *}\right) p=0.001$, ANOVA, Tukey's post-test. 

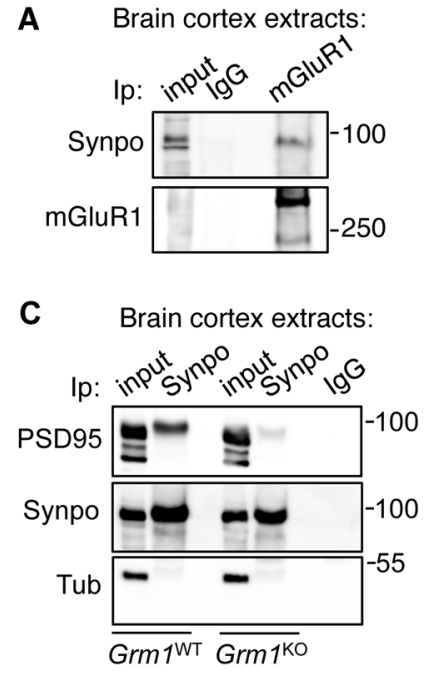

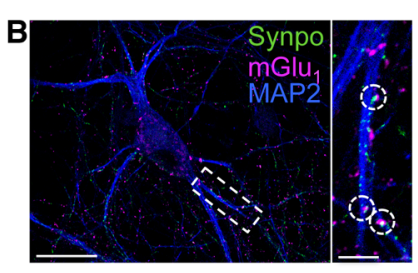

D

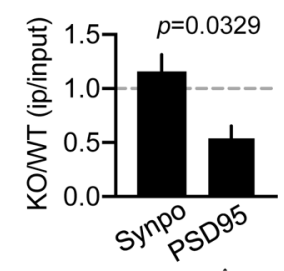

Figure 6. mGluR1 enables Synpo stabilization at excitatory spine synapses.

A. Synpo co-precipitates with mGluR1: representative immunoblot probed for Synpo of immunoprecipitation (Ip) with anti-mGluR1 or control IgG from lysates of brain cortex of adult WT mice.

B. Representative images of hippocampal neurons labeled for mGluR1, Synpo and MAP2: mGluR1 puncta are found in apposition to Synpo. Scale bar $50 \mu \mathrm{m}$; inset, $10 \mu \mathrm{m}$.

C. Co-precipitation of PSD95 with Synpo in $\mathrm{Grm} 1^{\mathrm{WT}}$ and $\mathrm{Grm} 1^{\mathrm{KO}}$ mice: representative blot probed for PSD95 of immunoprecipitation with anti-Synpo antibody from lysates of brain cortex of adult $\mathrm{Grm} 1^{\mathrm{WT}}$ and $\mathrm{Grm} 1^{\mathrm{KO}}$ mice. Input, $5 \%$ of Ip lysate; Tubulin (Tub), loading control.

D. Quantification of PSD95 co-precipitation with Synpo from blots as in (b). Mean \pm SE, KO/WT PSD95 $0.54 \pm$ 0.12 , KO/WT Synpo $1.2 \pm 0.16, \mathrm{~N}=3$ mice per group, two-tailed unpaired t-test. 

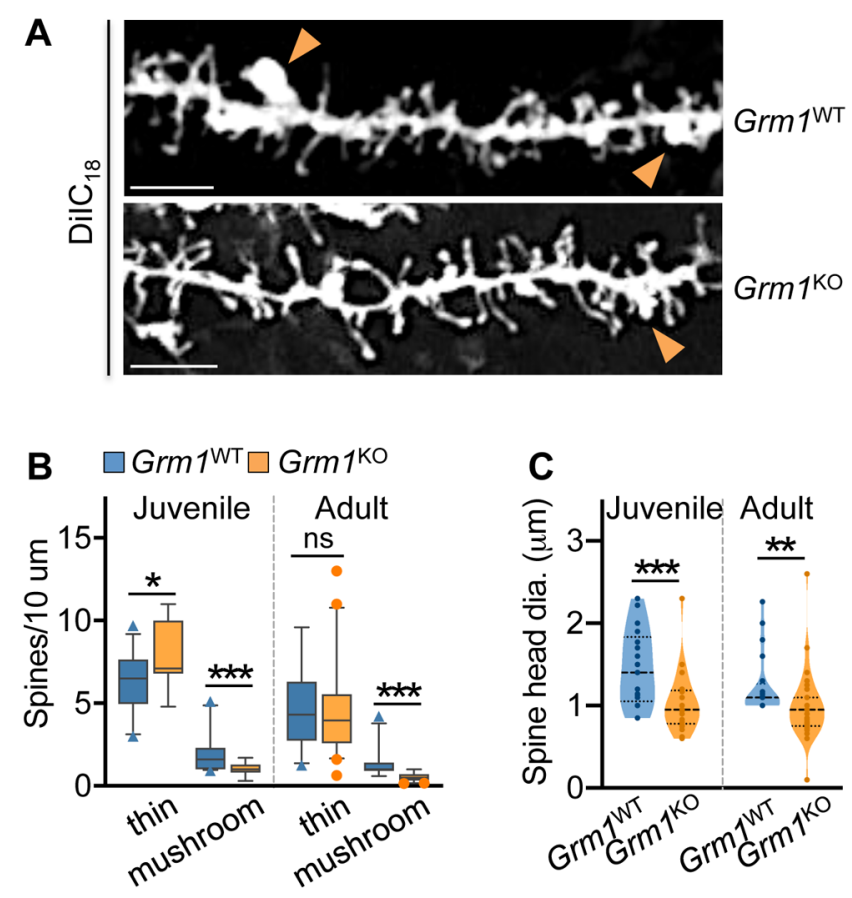

Figure 7. Reduced density and growth of mushroom spines in mice lacking mGluR1.

A. Representative images of DilC $_{18}$-labeled dendritic branches in the brain cortex of adult $\mathrm{Grm} 1^{\mathrm{WT}}$ and Grm $1^{\mathrm{KO}}$ mice; scale bars $10 \mu \mathrm{m}$.

B. Quantification of spine density per $10 \mu \mathrm{m}$ in the cortex of $\mathrm{Grm} 1^{\mathrm{WT}}$ and $\mathrm{Grm} 1^{\mathrm{KO}}$ mice from images as in (a). Juvenile ( 1.5 month-old), mean \pm SD thin spines WT $6.8 \pm 1.7$ ( $n=32$ dendritic branches), KO $7.8 \pm 1.9$ $(\mathrm{n}=25),\left(^{*}\right) p=0.025$; mushroom spines WT $1.9 \pm 0.98(\mathrm{n}=34)$, KO $1.10 \pm 0.39(\mathrm{n}=19), \mathrm{N}=2$ mice per group; $\left({ }^{* * *}\right) p<0.001$. Adult mice ( 7-12 month- old), mean \pm SD thin spines WT $4.7 \pm 2.2(\mathrm{n}=36)$, KO $4.4 \pm 2.5$ ( $\mathrm{n}=46)$, (ns) $p=0.29$; mushroom spines WT $1.4 \pm 0.87(\mathrm{n}=31)$, KO $0.54 \pm 0.25(\mathrm{n}=39), \mathrm{WT} N=5, \mathrm{KO} N=4$ mice $\left({ }^{* * *}\right) p<0.001$, Mann-Whitney test.

C. Quantification of mushroom spine head dimensions (diameter) in Grm $1^{\mathrm{WT}} \mathrm{Grm} 1^{\mathrm{KO}}$ mice. Juvenile, mean \pm $\mathrm{SD}, \mathrm{WT} 1.5 \pm 1.7 \mu \mathrm{m}(\mathrm{n}=21)$, KO $\left.1.0 \pm 0.36 \mu \mathrm{m}(\mathrm{n}=25){ }^{* * *}\right) p=0.001$; adult, mean $\pm \mathrm{SD}, \mathrm{WT} 1.2 \pm 0.38$ $(\mathrm{n}=20)$, KO $\left.1.0 \pm 0.40(\mathrm{n}=40),{ }^{* *}\right) p=0.003$, Mann-Whitney test. 